\title{
Erratum to: Phreatophytes under stress: transpiration and stomatal conductance of saltcedar (Tamarix spp.) in a high-salinity environment
}

\author{
Edward P. Glenn • Pamela L. Nagler • \\ Kiyomi Morino $\cdot$ Kevin R. Hultine
}

Published online: 3 August 2013

(C) Springer Science+Business Media Dordrecht 2013

\section{Erratum to: Plant Soil \\ DOI 10.1007/s11104-013-1803-0}

The original version of this paper should have contained the following statement in the Acknowledgment section: Any use of trade, product, or firm names is for descriptive purposes only and does not imply endorsement by the U.S. Government.

The online version of the original article can be found at http:// dx.doi.org/10.1007/s11104-013-1803-0.

\section{E. P. Glenn ( $\bowtie)$}

Environmental Research Laboratory, Department of Soil, Water and Environmental Science, University of Arizona, 2601 East Airport Drive, Tucson, AZ 85706, USA

e-mail: eglenn@ag.arizona.edu

\section{P. L. Nagler}

U.S. Geological Survey, Sonoran Desert Research Station, Southwest Biological Science Center,

University of Arizona, Tucson, AZ, USA

\section{K. Morino}

Laboratory of Tree Ring Research, University of Arizona,

Tucson, AZ, USA

K. R. Hultine

Desert Botanical Garden, Phoenix, AZ, USA 